\title{
Computational Fluid Dynamics in Microreactors Analysis and Design: Application to Catalytic Oxidation of Volatile Organic Compounds
}

\section{Odiba S, Olea M*, Hodgson S, Adgar A and Russell PA}

School of Science and Engineering, Teesside University, Borough Road, Middlesbrough TS1 3BA, UK

\begin{abstract}
This paper deals with the design of a suitable microreactor for the catalytic oxidation of volatile organic compounds (VOCs). There are a number of ways to release VOCs into the atmosphere, typically during processing of natural gas and handling petroleum products. As VOCs are harmful to our health, there is increased scientific interest in developing technologies for their destruction. Catalytic oxidation is one of them. Microreactors have showed higher efficiency than the conventional ones, mainly due to their large surface area to volume ratio and excellent heat and mass transfer properties. The design of a microreactor can be explored based on simulation results obtained by using computational fluid dynamics (CFD) package of COMSOL Multiphysics. The first design step, based on cold flow simulation, was the selection of the most suitable microreactor geometry and configuration. Four different geometries had been proposed and simulated to evaluate the fluid behaviour in the microchannels. One of them, Type A2, allowed the most uniform flow distribution in all channels, as assessed through relative standard deviation calculations. The second design step involved the investigation of the VOCs catalytic oxidation, using propane as model molecule, occurring in the microreactor with the geometry/configuration previously found. The proposed microreactor consists of eleven parallel channels of square cross-section, with $0.5 \times 10^{-3} \mathrm{~m}$ width, $0.5 \times 10^{-3} \mathrm{~m}$ height and $0.1 \mathrm{~m}$ length. The catalytic microreactor was simulated for temperatures between $563 \mathrm{~K}$ and $663 \mathrm{~K}$ and inlet flow velocities from 0.01 to $1.00 \mathrm{~m} \cdot \mathrm{s}^{-1}$. The exit propane conversion increased rapidly with increasing temperature for a fixed inlet flow velocity. For a fixed temperature, the propane conversion increased as the inlet flow velocity decreased.
\end{abstract}

Keywords: Volatile organic compounds oxidation; Catalytic microreactor design; CFD modelling; Propane

\section{Introduction}

In recent years, constraints imposed by the increasingly stringent environmental regulations and safety awareness, coupled with increasing competition, have put great stress on traditional chemical industry. Development and implementation of more sustainable chemistry and chemical technologies is one of the most essential requirements for the chemical industry to survive for the future. These challenges drive innovations in both chemistry and chemical engineering.

Implementation of any chemical engineering development that leads to substantially smaller, cleaner, and more energy-efficient technologies is probably the most popular strategy for developing new chemical processes and equipment [1]. This is possible by challenging technologies for sustainable manufacturing such as the use of ecoeffeciency, inherent safety with improved quality of the product, reduced environmental impact, rapid plant response and great possibilities for distributed manufacturing [2,3]. Recently, there were a number of process intensification approaches and these include intensification of mass transfer in static mixers [4,5], micromixers [6,7] and rotating packed bed $[8,9]$, intensification of heat transfer using compact/micro heat exchangers $[10,11]$ and nanofluids [12], integration of processes in one multifunctional step to reduce plant size and increase process efficiency, for instance, reactive distillation and membrane reactor [13-15], and adoption of new reactors such as compact/microreactors $[16,17]$, heat exchange reactor [18], spinning disk [19], impinging jets reactors [20] and ZoneFlow ${ }^{\mathrm{TM}}$ reactor [21].

Among the above technologies, the emergence of microreaction technology and process miniaturization over the past two decades has provided a potentially new platform for accelerating the development of next-generation catalysts and multiphase catalytic process technologies for a wide variety of applications.

Microreactors are devices containing open paths for fluids with characteristic dimensions in the range of $100-500 \mu \mathrm{m}$ and have multiple channels where the chemical transformations occur [22]. These new devices offer promising avenues toward more precise control over transport phenomena and reaction characteristics than is possible with traditional reaction technology. The differences between microreactors versus traditional reactors arise from the small dimensions of the channels and vessels, and the high surface-to-volume ratio in microreactors. Microreactor technology is gaining increasing importance in pharmaceutical synthesis, chemical engineering and process technology because of the quest for clean and efficient on-site, on-demand and on-time distributed production of chemicals. The reactor being the heart of chemical production process has received increasing attention. Different reactions have been used to illustrate the advantages of performing chemical reactions in microreactors, which are particularly suitable for highly exothermic, endothermic and fast reactions. One of these reactions, the partial oxidation of toluene over $\mathrm{V} / \mathrm{Ti}$ oxide catalysts, was successfully performed in a microchannel reactor which provided higher selectivity and very good mass and heat transfer conditions, showing no hot spots compared to the traditional packed fixed-bed reactor [23]. The microreactors' small reaction volume allows handling of dangerous reactions such as those involving explosive or toxic components [24,25]. Due to their high surface-tovolume ratio, the microreactors are suitable for kinetically controlled reactions and high heat and mass transfer rates [26]. What is more, the scale-up can be easily performed just by multiplying the number (numbering-up) of the microreactors units without changing the

${ }^{*}$ Corresponding author: Olea M, School of Science and Engineering, Teesside University, Borough Road, Middlesbrough TS13BA, UK, E-mail: M.Olea@tees.ac.uk

Received June 21, 2016; Accepted June 28, 2016; Published July 06, 2016

Citation: Odiba S, Olea M, Hodgson S, Adgar A, Russell PA (2016) Computational Fluid Dynamics in Microreactors Analysis and Design: Application to Catalytic Oxidation of Volatile Organic Compounds. J Chem Eng Process Technol 7: 297. doi:10.4172/2157-7048.1000297

Copyright: ( 2016 Odiba S, et al. This is an open-access article distributed under the terms of the Creative Commons Attribution License, which permits unrestricted use, distribution, and reproduction in any medium, provided the original author and source are credited. 
channel's geometry. The use of microreactors at industrial scale requires a large number of reactors in parallel, since each reactor provides only a small volume dedicated to reaction. However, process design by this "numbering-up" (or scaling-out) approach is not exempt from some of the difficulties encountered in traditional scale-up. In particular, the parallel structures may exhibit poor uniformity in the fluid distribution between microchannels, which is generally undesirable. Equal fluid velocities in the microchannels are a necessary condition so as to have equal mass- and heat-transfer coefficients, and space times [25]. Catalyst material is usually deposited on the wall of the reacting channels, using different techniques, for catalytic microreactor $[27,28]$. A careful design of the microreactor is necessary to allow uniform flow distribution within the channels especially for constant flow reaction. For a highly exothermic reactions coupled with heat transfer in a microreactor, non-uniform distribution may locally reduce the exchanged heat flux yielding to the formation of hazardous hot spots. It has been reported that microreactor devices run safely under conditions, which lay in the explosion regime [22,29-31]. For instance, the strongly exothermic o-xylene oxidation to phthalic anhydride was operated safely in the explosive regime in a microfixed bed reactor at high temperature $[32,33]$. Usually, microreactors are operated under laminar flow conditions. The performance of the microreactors relies strongly on the manifold and channel design. Plug flow reactor model can give good predictions of reaction conversions and selectivity but it has been reported that the axial and the radial profile of the chemical species and the temperature profile are unsatisfactorily predicted because the plug flow reactor model excludes the effects of transport phenomenal [34]. Computational fluid dynamics (CFD) modelling with reaction kinetics is widely used to obtain more satisfied results.

Modelling helps to obtain information for the understanding of a system and consequently to be able to predict its behaviour. Model development requires the consideration of transport phenomena, thermodynamics and kinetics involved in the chemical and physical process during the reaction. The simulation and modelling based on computational fluid dynamics have attracted increasing interest and have been successfully applied to the analysis and design of microflow devises [35-39].

Based on this rather comprehensive literture search, we concluded that microreators are suitable for the catalytic elimination of volatile organic compounds (VOCs). The application of microreactor technology to catalytic oxidation reactions is proving to be advantageous due to the ability to avoid problems such as high exothermicity and poor control of reaction conditions, commonly associated with catalytic oxidation reactions [30]. The small inventories of catalyst and reactants in a microreactor result in a process requiring only a few milligrams of catalyst and allowing operation within the flammability limits. Among their potential advantages for chemical processes, the very small thermal inertia, allowing for a very direct control of temperature as a very critical reaction parameter, is an important one.

Because of concerns over ground-level ozone formation and regional air quality, the Commission of the European Communities has promulgated a directive dealing with solvent emissions, the Solvents Emissions Directive, SED [40]. The Solvent Emissions Directive (SED) is the term for the Council Directive 1999/13/EC on the limitation of emissions of volatile organic compounds due to the use of organic solvents in certain activities and installations. The pupose of the Directive is to prevent or reduce the direct and indirect effects of emissions of VOCs into the environment and the potential risks to public health by providing measures and procedures to be implemeted for certain activities operating above defined solvent consumption thresholds. As a consequence, industry is required to reduce its emissions of volatile organic compounds (VOCs) in general, and solvents in particular. A consequence of the uncontrolled emission of VOCs, in general, and solvents, in particular, is that they may act as greenhouse gases and hence there may be climate change consequences. Considerable quantity of volatile organic compounds are emitted into indoor/outdoor air from building materials such as paints, home and personal care products such as pesticides, air fresheners, tobacco smoking, industrial processes and transportation activities (TSI, 2013). Different technologies have been developed for the elimination of volatile organic compounds such as recovery process by seperation, absorption or adsorption and destruction process either by thermal or catalytic oxidation. Catalytic oxidation is one of the most promising elimination techniques for VOCs as a results of its flexibility and energy saving. The catalytic materials enhance the chemical reactions that convert VOCs into carbon dioxide and water.

The main aim of this work is to study and develop a suitable microreactor model for VOCs catalytic oxidation using the CFD package of COMSOL Multiphysics. The objectives are to investigate the behaviour of cold flow (without reaction), air flow in this case, within the microchannels; to determine the most suitable geometry and configuration of the reactor, using 2-D CFD simulations; to study the reactive flow by assessing the propane oxidation reaction occurring in the microreactor with the already proposed geometry, based on an available kinetic model, using 3-D CFD simulations. Propane was chosen as model molecule because reaction conditions, catalysts and kinetics are well known for macroscopic conditions [41].

\section{Proposed approach to microreactor design}

When designing microreactors, several critical microreactordesign issues should be considered. These are as follows: the reactor structure (configuration), the reactor shape and size, packaging and connecting, pressure drop constraints, residence time and thermal constraints, robustness, and mechanical stability. Although different cross-sections such as rectangular, circular, trapezoidal, triangular, and elliptical were investigated by several researchers to understand the flow behaviour in microchannels, the rectangular cross-section was chosen for this study, mainly due to practical considerations such as fabrication techniques, cost, ease of manufacturing, as the final goal was to build the microreactor with the optimal configuration and to assess its performance against the modelled one. The rectangular shape is characterised by width $(W)$, height (or depth) $(H)$ and length $(L)$.

The residence time distribution (RTD) among parallel microchannels is one of the key design specifications for microreactors, because the poor uniformity in the distribution reduces the yield or the selectivity of reaction products. In spite of the recent advances in computational fluid dynamics, it is not practical to apply CFD simulations directly to the optimal design problem of microreactors due to their long computational time. As such, a two-stage modelling process was performed. First stage dealt with the microchannel modelling based on a simplified model, the dispersion model, while the second stage dealt with CFD simulations for the multichannel microreactor.

For the first stage, a narrow RTD for microchannels was assumed due to the small channel dimensions compared to typical channel length and short lateral diffusion times. The size of the microchannel was then calculated to comply with this narrow RTD. Next step was the estimation of the number of parallel microchannels, with the same cross-sectional area and length, to assure equal flow rates in all of them (numbering-up process). 
For the second stage, CFD modelling was firstly applied to study the air flow behaviour and then to study the behaviour of the reactive flow, a mixture of propane and air.

\section{Microchannel's shape and size selection}

In order to simplify the analysis presented further, several assumptions have been made:

- Isothermal air flow through the microchannels is assumed.

- Laminar flow conditions are assumed.

- Flow is fully developed and not disturbed by the microchannels feeding with absence of recirculation loops.

As mentioned above, a microchannel with a rectangular shape (cross-section) was chosen. For this, a hydraulic diameter, $d_{b}$, has to be calculated and then used to characterise the flow, defined as follows:

$$
d_{h}=\frac{4 \cdot A}{P}=\frac{4 \cdot \text { Cross }- \text { sec } \text { tional area }}{\text { wetted perimeter }}=\frac{2 W H}{(W+H)}=\frac{2 W}{\alpha+1}
$$

This approximation is however not valid for all rectangular shaped channels, the aspect ratio, $\alpha,(\alpha=W / H$, or $H / W$, for $0<\alpha<1)$ of the channel has to be calculated to take into account the laminar friction constant $f \cdot \operatorname{Re}$ (Darcy friction factor, $f$, times Reynolds number Re, or Poiseuille number). The effective diameter, $d_{e f p}$ can be calculated by Ref. [42]:

$$
d_{\text {eff }}=\left(\frac{64}{f \cdot \operatorname{Re}}\right) \cdot d_{h}
$$

The friction constant can be calculated from the following polynomial equation [43]:

$$
f \cdot \operatorname{Re}=96\left(1-1.3553 \alpha+1.9467 \alpha^{2}-1.7012 \alpha^{3}+0.9564 \alpha^{4}-0.2537 \alpha^{5}\right)
$$

The Reynolds number can be calculated as:

$$
\operatorname{Re}=\frac{\rho \cdot u \cdot d_{e f f}}{\mu}
$$

where $\rho$ is the density of the fluid, $\mathrm{kg} / \mathrm{m}^{3}, u$ is the flow velocity, $\mathrm{m} / \mathrm{s}, d_{\text {eff }}$ the effective hydraulic diameter, $\mathrm{m}$, and $\mu$ is the fluid dynamic viscosity, $\mathrm{kg} / \mathrm{m} \cdot \mathrm{s}$. For a laminar flow, $\operatorname{Re}<1700$ [44]. As seen in Table 1, for aspect ratios $<0.4, f \operatorname{Re}>64$, which means that the effective hydraulic diameter, $d_{e f f}$ is lower than the hydraulic diameter. Therefore, for a more efficient flow through the microchannels, aspect ratios higher than 0.4 were proposed and Re numbers were calculated for air flow velocities between 0.1 and $100 \mathrm{~m} / \mathrm{s}$. At room temperature, the air density is 1.205 $\mathrm{kg} / \mathrm{m}^{3}$, while its dynamic viscosity is $1.983 \times 10^{-5} \mathrm{~kg} / \mathrm{m} \cdot \mathrm{s}$ [45]. For a $W=0.5 \times 10^{-3} \mathrm{~m}$ (chosen based on practical considerations, mainly the ease of manufacturing), the results are presented in Table 2 below.

Based on the results presented in Table 2, microchannels with aspect ratio of 1 (or square cross-section) were chosen for further studies, as for this aspect ratio, the laminar flow is achieved for velocities up to 50 $\mathrm{m} / \mathrm{s}$, which will give a wider window of operation as compared with the microchannels with the other three aspect ratios. For a laminar flow, a parabolic velocity profile is assumed for which a narrow residence time distribution is expected. A narrow residence time distribution is desired as well, as for reactions with positive reaction order (as it is the catalytic combustion of propane), the reactor performance will decrease with the broadening of the RTD at constant mean residence time. The diffusion in the axial and radial directions plays an important role in RTD. The diffusion in the radial direction tends to diminish the spreading effect of the parabolic velocity profile, while in the axial direction the molecular diffusion increases the dispersion [46]. With

\begin{tabular}{|c|c|c|c|c|c|c|c|c|}
\hline \multirow{2}{*}{$\underset{(\mathrm{m} / \mathrm{s})}{u}$} & \multicolumn{4}{|c|}{$d_{\mathrm{eff}} \times 10^{3}(\mathrm{~m})$} & \multicolumn{4}{|c|}{$\operatorname{Re}$} \\
\hline & $\alpha=0.4$ & $\alpha=0.5$ & $\alpha=0.75$ & $\alpha=1$ & $\alpha=0.4$ & $\alpha=0.5$ & $\alpha=0.75$ & $\alpha=1$ \\
\hline 0.1 & \multirow{20}{*}{0.698} & \multirow{20}{*}{0.686} & \multirow{20}{*}{0.632} & \multirow{20}{*}{0.562} & 4 & 4 & 4 & 3 \\
\hline 0.2 & & & & & 8 & 8 & 8 & 7 \\
\hline 0.3 & & & & & 13 & 13 & 12 & 10 \\
\hline 0.4 & & & & & 17 & 17 & 15 & 14 \\
\hline 0.5 & & & & & 21 & 21 & 19 & 17 \\
\hline 0.6 & & & & & 26 & 25 & 23 & 20 \\
\hline 0.7 & & & & & 30 & 29 & 27 & 24 \\
\hline 0.8 & & & & & 34 & 33 & 31 & 27 \\
\hline 0.9 & & & & & 38 & 37 & 35 & 31 \\
\hline 1.0 & & & & & 42 & 41 & 38 & 34 \\
\hline 10 & & & & & 424 & 416 & 384 & 342 \\
\hline 20 & & & & & 848 & 833 & 768 & 683 \\
\hline 30 & & & & & 1272 & 1250 & 1152 & 1025 \\
\hline 40 & & & & & 1697 & 1667 & 1536 & 1366 \\
\hline 50 & & & & & 2121 & 2084 & 1920 & 1708 \\
\hline 60 & & & & & 2545 & 2501 & 2304 & 2049 \\
\hline 70 & & & & & 2696 & 2918 & 2688 & 2391 \\
\hline 80 & & & & & 3393 & 3334 & 3072 & 2732 \\
\hline 90 & & & & & 3817 & 3752 & 3456 & 3074 \\
\hline 100 & & & & & 4242 & 4169 & 3840 & 3415 \\
\hline
\end{tabular}

\begin{tabular}{|c|c|}
\hline $\boldsymbol{\alpha}$ & $\boldsymbol{f} \cdot \mathbf{R e}$ \\
\hline 0 & 96 \\
\hline 0.05 & 89.91 \\
\hline 0.1 & 84.68 \\
\hline 0.125 & 82.34 \\
\hline 0.167 & 78.81 \\
\hline 0.4 & 72.93 \\
\hline 0.5 & 65.47 \\
\hline 0.75 & 62.19 \\
\hline 1 & 57.89 \\
\hline
\end{tabular}

Table 1: Laminar Friction Constant for Various Aspect Ratio Rectangular Channels [42].

Table 2: Reynolds numbers for different aspect ratios and flow velocities.

the so-called Taylor-Aris correlation the axial dispersion coefficient, $D_{a x}$, can be predicted based on the molecular diffusion coefficient, $D_{m}$, the mean velocity of the stratified flow, the effective hydraulic diameter of the microchannel, and the geometry of the cross-section:

$$
D_{a x}=D_{m}+\chi \frac{u^{2} d_{e f f}^{2}}{D_{m}}
$$

with $\chi=1 / 119$ for square cross-section. The molecular diffusion coefficient for air is $2.2 \times 10^{-5} \mathrm{~m}^{2} / \mathrm{s}$ [47]. The axial diffusion coefficient for a flow velocity of $50 \mathrm{~m} / \mathrm{s}$ was calculated as $2.9 \times 10^{-5} \mathrm{~m}^{2} / \mathrm{s}$. In practice, the axial diffusion can be neglected for Bodenstein numbers equal or higher than 100 [46]. The Bodenstein number, Bo, is defined as the ration between the axial dispersion time, $t_{a x}=L^{2} / D_{a x}$, and the mean residence time, $\tau=L / u$, which is identical to the space time for reaction mixtures with constant density. For Bo $\rightarrow 0$, the axial dispersion time is short compared to the mean residence time resulting in complete backmixing in the reactor. For Bo $\rightarrow \infty$ no dispersion occurs. For square channels [46],

$$
B o \cong 119 \frac{D_{m}}{d_{e f f}^{2}} \frac{L}{u}
$$

Using the above equation, the length of the microchannel can be derived as: 


$$
L \cong \frac{B o}{119} \frac{d_{e f f}^{2}}{D_{m}} u
$$$$
\text { For Bo } \geq 100, L \geq 0.85 \frac{d_{e f f}^{2}}{D_{m}} u \text {. }
$$

Therefore, for the chosen microchannel and $u=50 \mathrm{~m} / \mathrm{s}, \mathrm{L} \geq 0.6$ $\mathrm{m}$. For $u=0.1 \mathrm{~m} / \mathrm{s}, \mathrm{L} \geq 1.2 \times 10^{-3} \mathrm{~m}$. Since the microreactor with the optimum geometry and configuration is foreseen to be used as a mobile devise for indoor VOCs catalytic combustion, a microchannel length of $0.1 \mathrm{~m}$ was chosen. For this length, and for Bo numbers higher than 100 , the air flow velocity should be lower or equal to $10 \mathrm{~m} / \mathrm{s}$. Under these conditions, the microchannel can be considered as a plug flow reactor.

To conclude, a square cross-section microchannel was chosen, with $W=H=0.5 \times 10^{-3} \mathrm{~m}$ and $L=0.1 \mathrm{~m}$. Another important parameter to characterize the flow through the microchannels is the pressure drop, $\Delta p$. According to Debray et al. [48], in a laminar regime, the pressure drop of the air flow can be estimated as follows:

$$
\Delta p=\frac{96}{\operatorname{Re}} \cdot \frac{\rho \cdot u^{2}}{2} \cdot \frac{L}{2 \cdot H}
$$

For the square cross-section microchannel chosen, for $\mathrm{Re} \leq 1700$, $u=10 \mathrm{~m} / \mathrm{s}, \Delta p \leq 340 \mathrm{~Pa}$. This corresponds to a $\Delta p / L$ less than $3.4 \mathrm{kPa}$ $\cdot \mathrm{m}^{-1}$, which can be neglected.

\section{Numbering-up process}

The dispersion model is based on one single parameter, describing the residence time behaviour for simple cases using plug flow and perfect back mixing as the two limiting cases. Microstructured devices, however, are in many cases more complex than a single pipe flow that is well described by the dispersion model; they are multi-scale networks. Microstructured reactors consist of a number of microchannels in parallel (one scale), and inlet and outlet distributions sections (another scale) that cannot be included in one parameter. Appropriate design for uniform flow distribution is a key feature to ensure optimal performance of these channel networks. The numbering-up estimation was based on the results of a hydrodynamic analysis of these multi-scale networks, which was performed in order to determine the number of microchannels in parallel, with minimum flow maldistribution. The analysis followed a procedure described in detail by Saber et al. [49]. Briefly, the geometrical design of various channel networks is based on a similar multi-scale approach. In order to optimize the global performance of these systems, the first design criterion consists in optimizing the flow uniformity in the parallel channels, so that each channel operates under identical conditions. By using the successive steps of the multi-scale approach to ensure optimal flow distribution, the geometrical parameters of the networks, i.e., the internal hydrodynamic resistances, are constrained in order to reduce the required pumping power. The first part of this study focused on the flow behaviour through networks including two scales, i.e., the microchannel scale and the distributor scale. This hydrodynamic study was performed using isothermal and laminar flow model, which relates linearly the pressure drop to the flow rate through each part of the device.

For an array of microchannels an even distribution of the flow to the channels cannot be assumed generally. The main impact factors for the flow distribution to an array of microchannels are [49]:

1. Geometry of the distribution sections (optimised for even distribution or not).

2. Geometry of the microchannels.

3. Flow profile in the inlet section.

\section{Non-constant fluid properties.}

\section{Tolerances of channel geometry.}

Flow non-uniformities in the network can have different impacts on the system performance depending on the operation performed in the network and on the required design objectives. From an engineering point of view, several definitions of the flow maldistribution can be adopted. For example, if flow non-uniformities are likely to create a local hot spot and consecutive thermal runaway of the reactor, the conservative definition of the flow maldistribution should include the extreme flow differences, i.e., minimum and maximum values with respect to the nominal flow rate. The flow maldistribution in microchannels can then be defined as:

$$
\operatorname{Md}(\%)=\frac{\max (F)-\min (F)}{\max (F)} \times 100
$$

Where $F$ denotes the vector-grouped flow rates through the $n$ microchannels.

On the contrary, if the flow variations through the entire network are the key factor (e.g., for the performance of a given reaction), the flow maldistribution should include the standard deviation of all flow rates with respect to the average flow rate. The flow maldistribution can then be defined as:

$$
S d=\frac{\sqrt{1 /(n-1) \sum_{i=1}^{n}\left(F_{i}-\bar{F}\right)^{2}}}{F} \times 100
$$

Where $S d$ is the relative standard deviation and $\bar{F}$ denotes the average value of the vector $F$.

As at this stage the focus was on the hydrodynamic flow behaviour through microchannel networks, the flow maldistribution " $M d$ " defined by Eq. 9, that represents an extremely unfavourable case, was used as criterion of interest for flow uniformity. As shown in Figure 1, the maldistribution through two-scale networks depends on channel number and on ratio $r$, which is the ratio between the flow resistance through the channel and the flow resistance through the distribution or collection tube. It is obvious that flow maldistribution increases by increasing the number of parallel channels. However, this increase is more rapid and significant with low-resistance ratio values than with large ones. The flow resistance through a channel of scale $i, R_{i}$, depends on the length and diameter of this duct and flow viscosity, and is defined as:

$$
R_{i}=\frac{128 \cdot \mu \cdot L_{i}}{\pi \cdot D_{i}^{4}}
$$

The results presented in Figure 1 are valid for networks of different microchannel shapes, exhibiting linear relation between the pressure drop and the throwing flow rate and presenting resistance ratios ranging from $10^{2}$ to $5 \times 10^{4}$. As such, the set of curves in this figure makes possible to rapidly give a first estimate of the flow maldistribution at the initial design stage of multi-scale networks. The results analysis of this hydrodynamic study enables to propose some guidelines for the design of multi-channel networks. With the absence of constraints related to the volume of the distributor manifold or the overall number of parallel channels, optimal two-scale configurations yielding to the most uniform flow distribution and reducing the total pressure drop consist in designing distributor and collector manifolds giving a very lowhydrodynamic resistance in comparison to that of the microchannels. This can be carried out by increasing the diameter ratio between the 


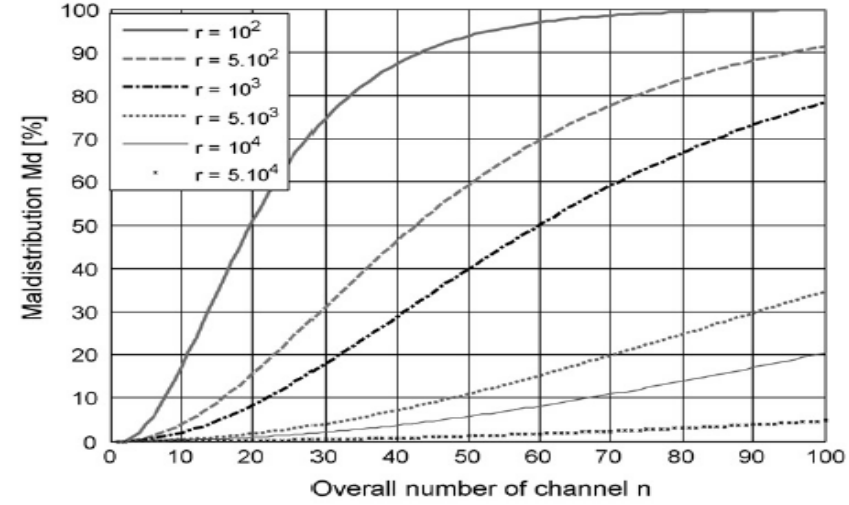

Figure 1: Evolution of the flow maldistribution through two-scale networks as a function of the channel number, $n$, for various values of the ratio $r$ [49].

distributor ducts and the microchannel and/or decreasing the length ratio between them. This makes it possible to ensure a uniform flow distribution through the channels of the structure [49].

Based on these findings, a microreactor consisting of 11 channels, with $L=0.1 \mathrm{~m}$ and $W=H=0.5 \times 10^{-3} \mathrm{~m}$ each, and with $0.5 \times 10^{-3} \mathrm{~m}$ of inter-channel distance was considered; 11 channels because odd number provided a better flow distribution considering the position of the inlet. According to Ref. [50], this microreactor can be described as a plate-fin microdevice since it has multi-microchannels, which are parallel to each other and have the same shape and size.

Besides of the number of branched microchannles and the microchannel's shape and size, the flow distribution is strongly affected by the shape and volume of the inlet and oulet manifolds. The main challenge of the design was to establish the manifold geometry which allows a uniform flow-distribution into the microchannels. Four different geometries, namely type A1, A2, A3, and A4, respectively, were proposed (Figure 2).

\section{CFD modelling of cold flow}

In order to obtain a quantitative indication of the flow behaviour in the multiple parallel microchannels, a 2-D model was developed and numerical simulations were performed for the four proposed geometries, using COMSOL Multiphysics software. COMSOL Multiphysics is a powerful interactive environment for modeling and solving all kinds of scientific and engineering problems based on partial differential equations (PDEs). When solving the PDEs, COMSOL Multiphysics uses the finite element method (FEM). In the finite element model, the geometry is divided in several triangles and the differential equations are solved for each node of the resulting mesh. The division of the geometry is called the meshing and should obey to some restrictions to guarantee the convergence of the calculations. The software runs the finite element analysis together with adaptive meshing and error control using a variety of numerical solvers. The main steps followed to develop a model with this software are presented in Figure 3. For the present study, the model assumes constant room temperature (since the model was developed for VOCs removal at room temperature). For this reason and due to the low pressure drop, constant value of air density was assumed. The Navier-Stokes equations for incompressible fluids along with the continuity equation were used to model the air flow [51]. The boundary conditions assumed were: noslip at the walls (which means that the fluid at the wall is not moving), fully developed laminar flow, uniform velocities for the inflow, and zero relative pressure for the outflow. This last boundary condition is physically equivalent to a boundary that is adjacent to a large container (inlet manifold) or exiting into a large container (outlet manifold).

The Navier-Stokes equations (conservation of momentum):

$$
\rho \frac{\partial u}{\partial t}+\rho u \cdot \nabla u=-\nabla p+\nabla \cdot\left(\mu\left(\nabla u+(\nabla u)^{T}\right)-\frac{2}{3} \mu(\nabla \cdot u) I\right)+F_{v}
$$

and the continuity equations (conservation of mass):

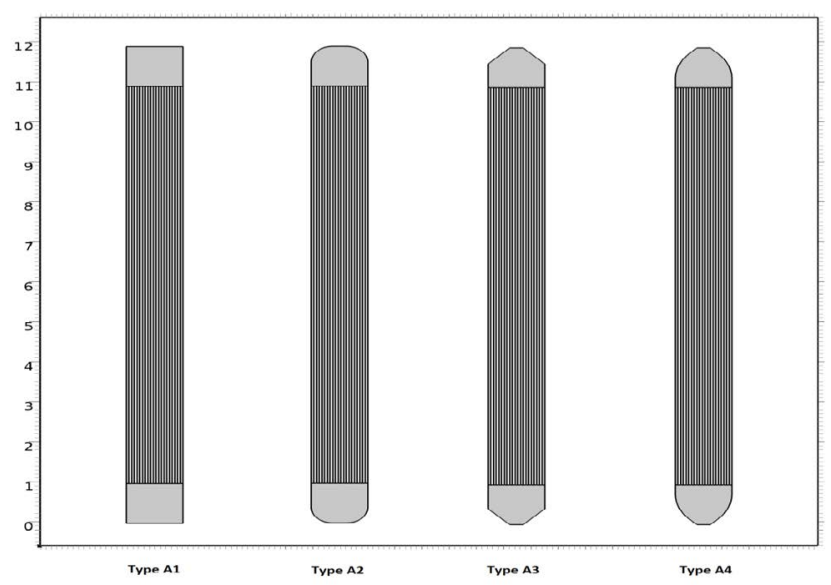

Figure 2: Four proposed geometries: Type A1, Type A2, Type A3 and Type A4, respectively.
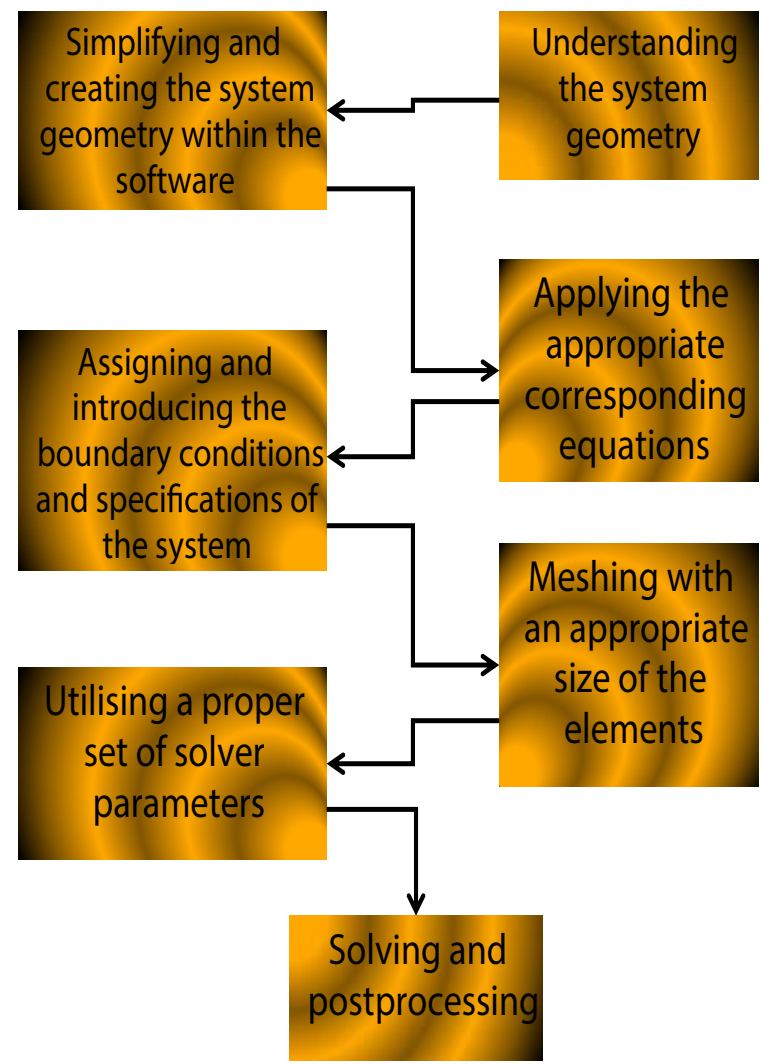

Figure 3: Main steps for developing a model with COMSOL Multiphysics software. 


$$
\frac{\partial \rho}{\partial t}+\nabla \cdot(\rho u)=0
$$

where $\rho$ is the solution's density $\left(\mathrm{kg} / \mathrm{m}^{3}\right), \mu$ dynamic viscosity of the fluid $\left(\mathrm{Ns} / \mathrm{m}^{2}\right), u$ is the velocity vector $(\mathrm{m} / \mathrm{s}), I$ denote the identity matrix, $F_{\mathrm{v}}$ is the volume force vector $\left(\mathrm{N} / \mathrm{m}^{3}\right), T$ is the absolute temperature $(\mathrm{K})$ and $p$ is pressure $(\mathrm{Pa})$. Another indication that the flow in this microreactor can be assumed as incompressible is that the Mach number (Ma) is much less than 0.3 for flow velocities $\leq 10 \mathrm{~m} / \mathrm{s}$ [51]. Resolving a parabolic or laminar flow profile requires at least two elements across each channel. This model was resolved with a refined mesh with five elements across each channel. The default element type for laminar flow is a linear element, so a number of linear segments are resolved due to the curved nature of the profile. Mesh is built to optimally resolve the laminar flow in the channels. First by modifying the geometry, an extra rectangle (channel) was added, in order to introduce a boundary "edge" along the top and bottom faces of each channel. Then an edge mesh was built for the channel inlets with a maximum element size of $1.25 \times 10^{-5} \mathrm{~m}$ per channel. Mapped mesh was then used in the channel domains to achieve a rectangular element that have a long aspect ratio since flow is likely to have a similar profile down the channels. This uses a default mesh size of fluid dynamics and coarse that is inherited from the global size node. Meshing is completed using a free triangular mesh on the remaining domains with fluid dynamics and extra-fine on the boundaries and coarse in the bulk. The fluid flow rates inside the channels were calculated by integrating across the normal component of the exit velocity. Since the flow is stationary and incompressible, the flow into and out a channel is equivalent. The velocity is non-uniform (laminar profile) across the cross-section. Preliminary simulation showed that the chosen meshes provided simulation results that were grid-independent (Figure 4). The mesh quality was evaluated by using the metrics provided by the COMSOL software, the Aspect Ratio (AR).

A 2 dimensional model of parallel rectangular microchannels with integrated inlet and outlet manifolds was developed for those four proposed geometries and the flow behaviour was simulated for flow velocities between $0.01 \mathrm{~m} / \mathrm{s}$ and $100 \mathrm{~m} / \mathrm{s}$. When solving the model for higher fluid flow velocities $(10 \mathrm{~m} / \mathrm{s}-100 \mathrm{~m} / \mathrm{s})$, the computation becomes highly non-linear, and the non-linearity of the computation can be thought of as a function of the Reynolds number. This can be solved by using a continuation sweep to incrementally increase the Reynolds number. In Figure 5 represents the contour plot of the velocity distribution inside the manifold and the channels for the four geometries. For Type A1, dead space is formed around the corner of the manifold. Dead space broadens residence time distribution. In order to design a manifold having less dead space, the corner of the manifold is trimmed away from the initial design 'Type A1' to formed Type A2 and further to Type A3 and Type A4, respectively. Flow patterns are simulated by CFD for the four geometries to determine which geometry achieves more uniform flow distribution.

Variations in fluid distribution were assessed by using the relative standard deviation (Eq. 10), as a measure of the quality of the flow distribution in the microchannels. A larger value of the relative standard deviation will correspond to a less uniformly distributed flow over the channels. The non-uniformity of flow residence time decreases the performance of catalytic microreactors.

\section{CFD modelling of catalytic propane oxidation} below:

Propane complete oxidation is described by the chemical equation

$$
\mathrm{C}_{3} \mathrm{H}_{8}+5 \mathrm{O}_{2} \rightarrow 3 \mathrm{CO}_{2}+4 \mathrm{H}_{2} \mathrm{O}
$$

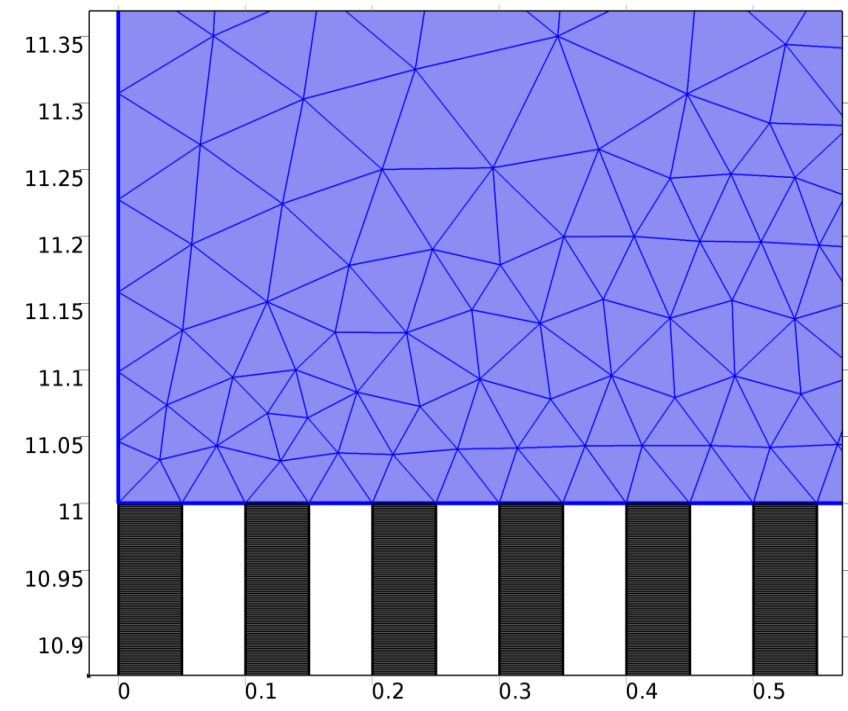

Figure 4: Triangular mesh used for the developed model.

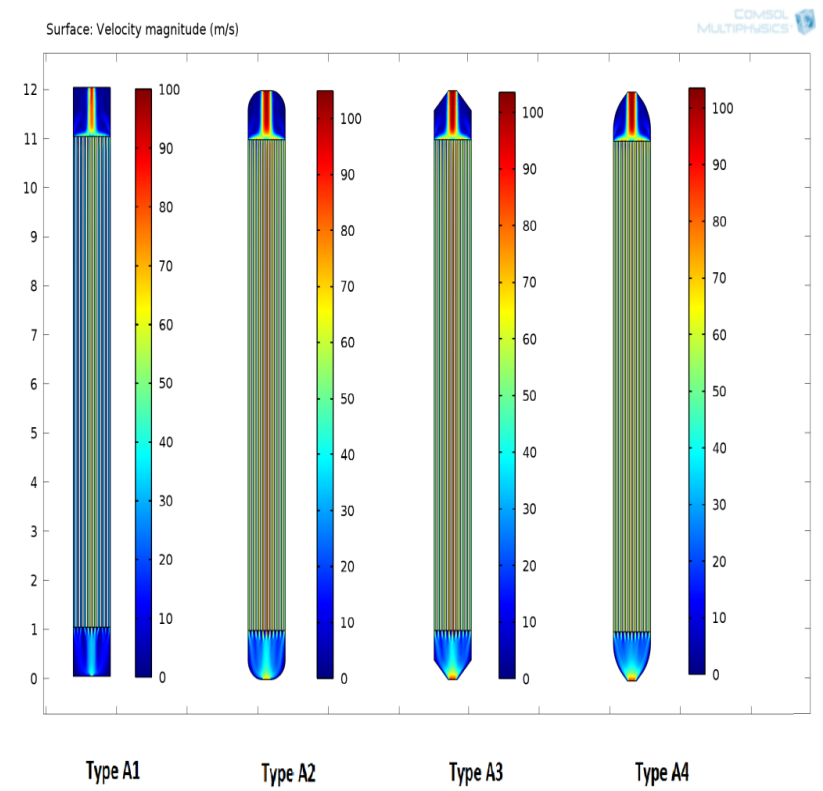

Figure 5: CFD simulations results for the four proposed geometries, showing the contour plot of velocity distribution.

Propane catalytic oxidation was modelled considering the microchannels walls as sources of products and sinks of reactants. It has been assumed that a thin and homogeneous layer of an appropriate catalyst, $\mathrm{Cr} / \gamma-\mathrm{Al}_{2} \mathrm{O}_{3}$ catalyst in this case [41], has been uniformly deposited onto the channels walls. Air was considered in large excess and as such, the operation of the microreactor was assumed as isothermal. A 3-D model was developed to describe the gas flow and reaction within the microreactor and solved for an ideal gas, laminar flow and convective transport of diluted species, and, along with the well-defined kinetics, for the composition of chemical species inside of the microchannels.

The inlet concentrations and flow density was derived from the partial pressures. The calculated flow field served as input to the transport of dilute species to the interface, to describe the convective 
mass transport. The mass transport with reaction in the reactor domain is given by the following equation:

$$
\frac{\delta c_{i}}{\delta t}+u \cdot \nabla c_{i}=\nabla \cdot\left(D \nabla c_{i}\right)+R_{i}
$$

where $D$ is the diffusion coefficient $\left(\mathrm{m}^{2} \cdot \mathrm{s}^{-1}\right), c_{i}$ is the concentration of species $i\left(\mathrm{~mol} \cdot \mathrm{m}^{-3}\right), u$ is the velocity vector and $R_{i}$ is the reaction rate for species $i\left(\mathrm{~mol} \cdot \mathrm{m}^{-3} \cdot \mathrm{s}^{-1}\right)$. The first term on the left-hand side of Equation 15 represents the accumulation or consumption of the species. The second term on the left hand side accounts for the convective transport due to a velocity field $u$. This field can be obtained from coupling the transport of diluted species to the one that describes the fluid flow (CFD or momentum balance). The first term on the right-hand side of Equation 15 accounts for the diffusion transport (interaction between the dilute species and solvent). Finally, the second term on the righthand side represents a source, or a sink term, usually due to a chemical reaction. In the microchannel, the boundary condition for a reactive inflow is set as $C=c_{i n}$. The oxidation of propane over the $\mathrm{Cr} / \gamma$ $\mathrm{Al}_{2} \mathrm{O}_{3}$ catalyst was well-described by a Mars-van Krevelen (reductionoxidation) mechanism and the rate equation was expressed as [41]

$$
R_{C_{3} H_{8}}=\frac{k_{O_{2}} k_{C_{3} H_{8}} P_{C_{3} H_{8}} P_{O_{2}}}{k_{O_{2}} P_{O_{2}}+5 k_{C_{H_{3}} H_{8}} P_{C_{H_{3}} H_{8}}}
$$

Where $k_{O_{2}}$ and $k_{C_{3} H_{8}}$ are the rate constants in the reduction oxidation mechanism $\left(\mathrm{mol} \cdot \mathrm{g}^{-1} \cdot \mathrm{min}^{-1} \cdot \mathrm{atm}^{-1}\right), P_{O_{2}}$ and $P_{C_{3} H_{8}}$ are the partial pressures of oxygen and propane and $R_{C_{3} H_{8}}$ is reaction rate of propane. The Arrhenius expression for the temperature dependence of $k_{C_{3} H_{8}}$ and $k_{C_{3} H_{8}}$ is:

$$
\begin{aligned}
& k_{O_{2}}=\mathrm{A}_{O_{2}} \exp \left(\frac{-\mathrm{E} a_{O_{2}}}{R T}\right) \\
& k_{C_{3} H_{8}}=\mathrm{A}_{C_{3} H_{8}} \exp \left(\frac{-\mathrm{E} a_{C_{3} H_{8}}}{R T}\right)
\end{aligned}
$$

where $A$ is the pre-exponential factor, $E_{a}$ is the activation energy (cal $\left.\cdot \mathrm{mol}^{-1}\right), R$ is the gas constant $\left(R=2^{a} \mathrm{cal} \cdot \mathrm{mol}^{-1} \cdot \mathrm{K}^{-1}\right)$, and $T$ is temperature in $\mathrm{K}$. The following values were determined: $A_{O_{2}}=1.36$ $\times 10^{12} \mathrm{~mol} \cdot \mathrm{g}^{-1} \cdot \mathrm{min}^{-1} \cdot \mathrm{atm}^{-1}, E_{O_{2}}=36000 \mathrm{cal} \cdot \mathrm{mol}^{-1}, A_{C_{3} H_{8}}=1.16^{2} \times 10^{10}$ $\mathrm{mol} \cdot \mathrm{g}^{-1} \cdot \mathrm{min}^{-1} \cdot \mathrm{atm}^{-1}$ and $E_{C_{3} H_{8}}=30000 \mathrm{cal} \cdot \mathrm{mol}^{-1}[41]$.

\section{Results and Discussion}

\section{Cold flow effect of total flow rate from manifold to channels}

This was tested by calculating relative standard deviation for the flow rates, and plotting the relative standard deviation against total flow rate, as shown in Figure 6. A significant difference between geometries $\mathrm{A} 1$, and $\mathrm{A} 2, \mathrm{~A} 3$ and $\mathrm{A} 4$ is observed. The relative standard deviations are an order of magnitude less for type A2, A3, and A4. However, above a transitional flow rate of $0.3 \mathrm{~m}^{3} / \mathrm{hr}$, the relative standard deviation was constant for type A2, A3, and A4. The relative standard deviation increases fast for type A1. It appears that the observed effect is linked to the dead space in the manifold. Type A2, with the lowest standards deviation, gave a better uniform flow distribution compare to the other geometries, namely Type A1, A3 and A4, respectively.

\section{Cold flow effect of inlet velocity}

This was tested by calculating the normalized flow rates and plotting the normalized flow rate against the channel number as seen in Figure 7. Normalized flow rate is calculated by dividing the actual flow rate per channel by the mean flow rate. For all geometries there

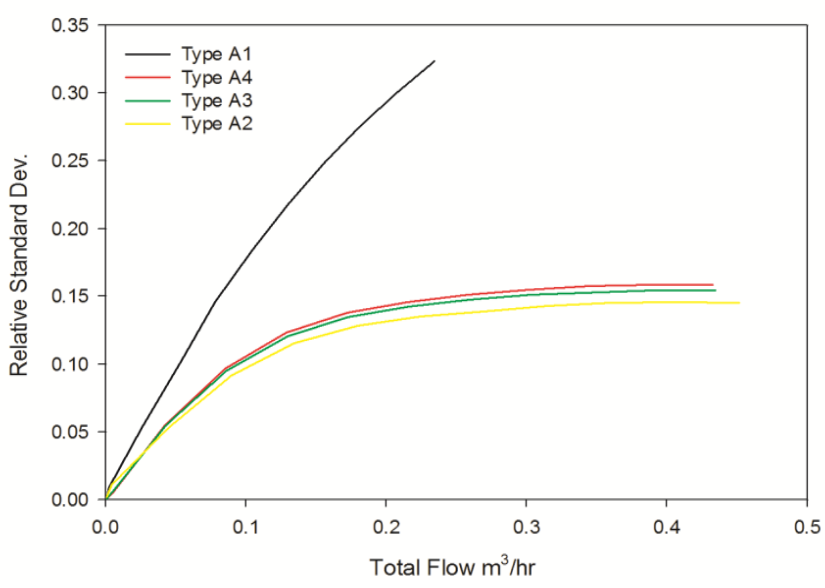

Figure 6: Relative standard deviation of the flow distribution as a function of total gas flow rate for the 4 geometries.

was an effect on the "outer" channels located furthest away from the manifold inlet. The flow was less for these channels compared to the "inner" channels near the inlet. The highest flow rates occurred for the centre channels. This was particularly pronounced for Type A1 which has a much narrowed active inlet area compared to Type A2, A3, and A4, respectively. This produced a more steep parabolic profile in the centre channels compared to Type A2, A3, and A4, respectively. At inlet velocities below $10 \mathrm{~m} / \mathrm{s}$, a constant flow rate is found, which means that the flow distribution is independent of flow rate. All the geometries (Type A1, A2, A3, and A4) gave similar results in this regime. In this region where the flow distribution is independent of the flow rate, the flow field is determined by wall friction. At an inlet velocity of $60 \mathrm{~m} / \mathrm{s}$ and above, inertial forces become important.

\section{Catalytic oxidation of propane}

The 3-D model was solved and the performance of the 11-channel microreactor with Type 2 configuration was assessed using the propane concentration and the fractional conversions, $X$, as well, and defined as:

$$
X=\frac{c_{\left(C_{3} H_{8}\right)_{\text {in }}}-c_{\left(C_{3} H_{8}\right)_{\text {out }}}}{c_{\left(C_{3} H_{8}\right)_{\text {in }}}}
$$

The simulations were performed for an initial concentration of propane of $0.2 \mathrm{~mol} \cdot \mathrm{m}^{-3}$, for temperatures between $563 \mathrm{~K}$ and $663 \mathrm{~K}$, and velocities between 0.01 and $1.00 \mathrm{~m} \cdot \mathrm{s}^{-1}$, which ensured a laminar $(0.34<\operatorname{Re}>34)$ and uniform flow within the channels. As such, the results of the integration of the model are showed over a single channel; the concentration profile for all channels is similar because of the even distribution of flow. The Figure 8 presents the 3 -D plot of the velocity profile showing the flow behaviour in the microchannels at temperature of $593 \mathrm{~K}$. Figure 9 is the $3-\mathrm{D}$ plot of the propane concentration profile along the channels for $593 \mathrm{~K}$ and inlet velocity of $0.1 \mathrm{~m} \cdot \mathrm{s}^{-1}$.

\section{Effect of temperature on propane concentration (conversion) at constant inlet velocities}

As shown in Figure 10, A, B, C and D the propane concentration at the exit of the microchannel decreases as the temperature increases for a constant inlet velocity, or in other words, the conversion of propane increases as the temperature increases. The temperature of the complete consumption of propane along the channel increases as the inlet velocity increases, from $593 \mathrm{~K}$ for inlet velocity of $0.01 \mathrm{~m} \cdot \mathrm{s}^{-1}$ to 

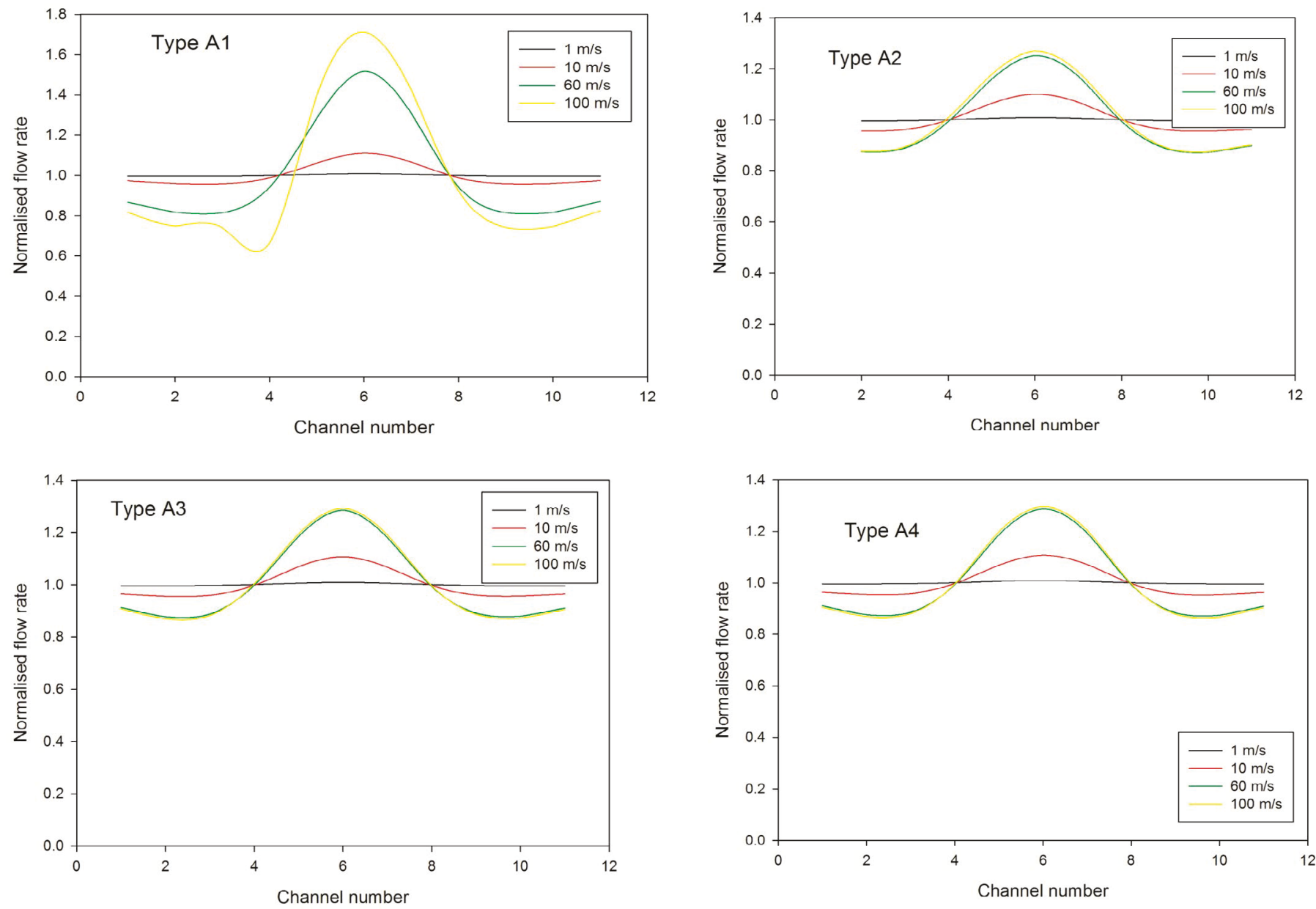

Figure 7: Flow distribution over the microchannels, calculated at an inlet velocity of $1 \mathrm{~m} / \mathrm{s}, 10 \mathrm{~m} / \mathrm{s}, 60 \mathrm{~m} / \mathrm{s}$ and $100 \mathrm{~m} / \mathrm{s}$, respectively.

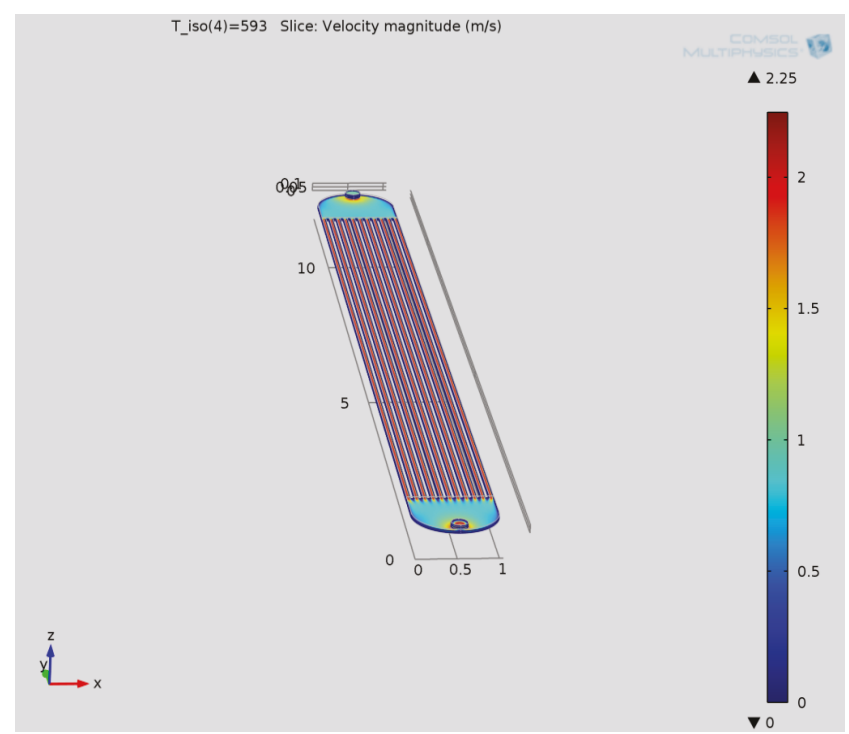

Figure 8: Velocity profile of the flow in the microreactor at temperature of $593 \mathrm{~K}$.

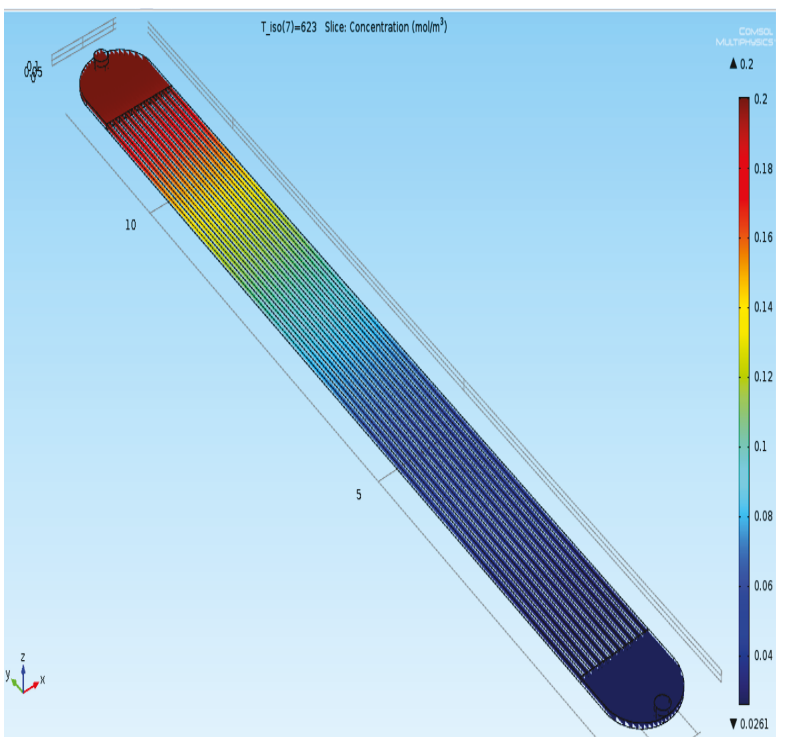

Figure 9: Propane concentration profile at temperature of $593 \mathrm{~K}$ and inlet velocity of $0.1 \mathrm{~m} \cdot \mathrm{s}^{-1}$. 


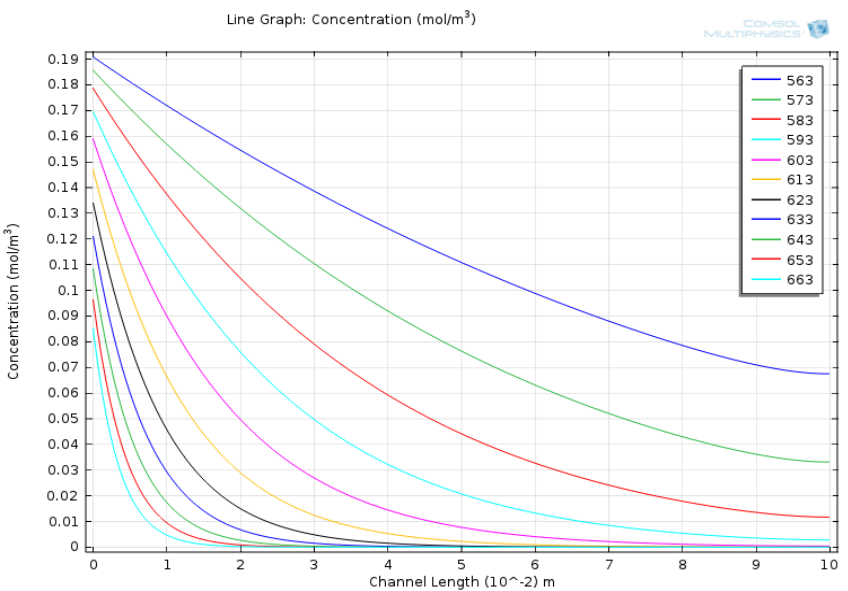

A

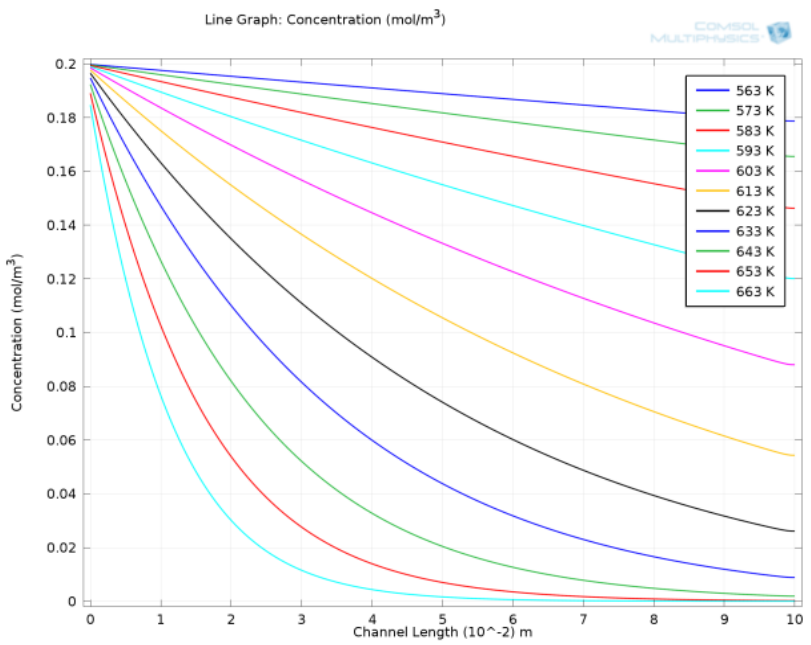

$\mathrm{C}$

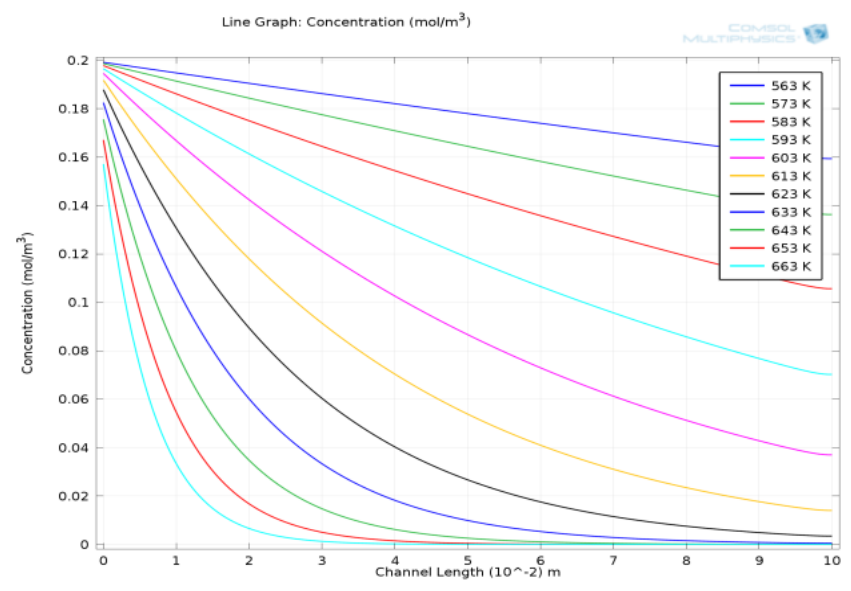

B

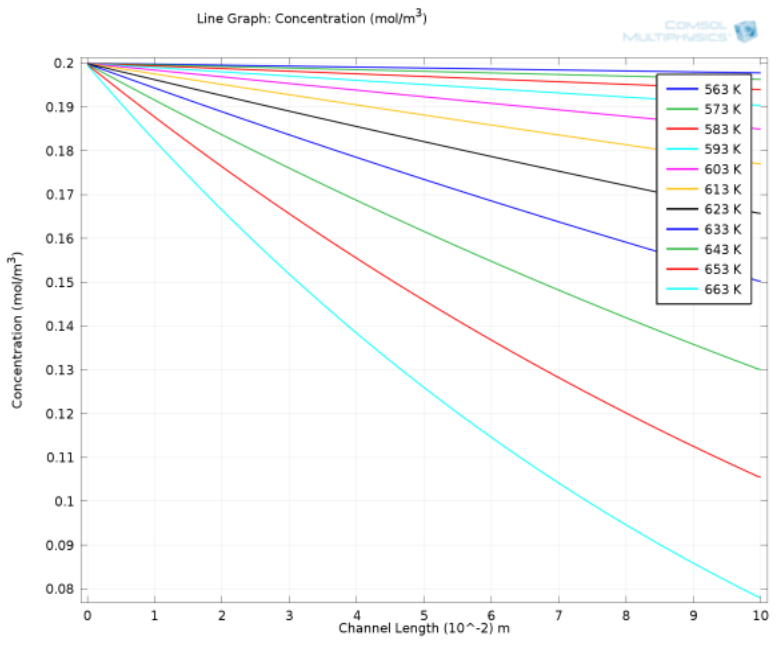

$\mathrm{D}$

Figure 10: Propane concentration along the channel at temperatures from $563 \mathrm{~K}$ to $663 \mathrm{~K}$ and different inlet flow velocities: $\mathrm{A}$ at $0.01, \mathrm{~B}$ at $0.05, \mathrm{C}$ at 0.1 and $\mathrm{D}$ at 1 $\mathrm{m} \cdot \mathrm{s}^{-1}$, respectively.

$663 \mathrm{~K}$ for inlet velocity of $1.00 \mathrm{~m} \cdot \mathrm{s}^{-1}$. This is evidence that there are not mass transfer limitations, which was expected due to the small size of the channel.

\section{Effect of inlet velocities on propane conversion at constant temperature}

In Figure 11 below presents the simulation results as propane exit conversion function of temperature, for different inlet flow velocities. For a constant temperature, the exit propane conversion increases as the inlet velocity decreases.

\section{Conclusion}

The use of a steady-state COMSOL Multiphysics model for the simulation of propane catalytic oxidation in a microreactor was demonstrated in this paper. Preliminary considerations and calculations allowed the selection of the microchannel size and shape

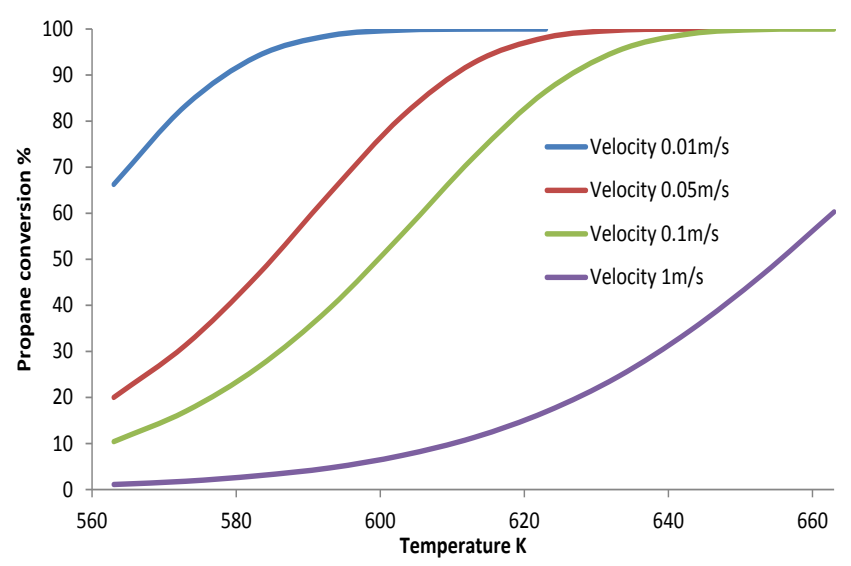

Figure 11: Propane exit conversion against temperature at inlet velocity of $0.01,0.05,0.1$, and $1 \mathrm{~m} / \mathrm{s}$, respectively. 
and the number of microchannels for the microreactor. The shape of the manifold was selected using a 2-D CFD model, and was based on the values of the relative standard deviation across the channels. The propane catalytic oxidation in the reactor previously proposed was studied using a 3-D CFD model.

Simulation results indicated two flow regimes depending on the inlet velocity for the 4 geometries. For all geometries at low flow rates (below $10 \mathrm{~m} / \mathrm{s}$ ), the flow distribution appears to be completely determined by wall friction. In this regime all 4 geometries yielded similar results. For operation below this velocity the flow distribution appears to be independent of flow rate. At flow rates above a transitional velocity $(60 \mathrm{~m} / \mathrm{s}$ for Type A2, A3, and A4 and $90 \mathrm{~m} / \mathrm{s}$ for type A1), inertial effects start to influence the flow distribution with a constant relative standard deviation. Geometries A2, A3, and A4 showed similar trends; for type $\mathrm{A} 1$ a different effect is observed, the relative standard deviation continues to increase until it appears to level off at a higher velocity. Type A2 gave the flow distribution with the lowest relative standard deviation. The 3-D simulation results showed that the exit propane conversion increased by increasing the temperature and by decreasing the gas inlet velocity, which supported the absence of mass transfer limitations, as expected.

\section{References}

1. Stankiewicz Al, Moulijin JA (2000) Process intensification: Transforming chemical engineering. Chemical Engineering Progress 96: 22-34.

2. Jenck JF, Agterberg F, Droescher MJ (2004) Products and processes for a sustainable chemical industry. A review of achievements and prospects. Green Chemistry 6: 544-556.

3. Perkins JD (1997) Process intesnsification in practice: Applications and opportunities. Antwerp, Belgium, Mechanical Engineering Publications Limited.

4. Bourne JR, Lenzner J, Petrozzi S (1992) Micromixing in static mixers: An experimental study. Industrial \& Engineering Chemistry Research 31: 1216-1222.

5. Thakur RK, Vial Ch, Nigam KDP, Nauman EB (2003) Static mixers in the process industries - A review. Chemical Engineering Research \& Design 81 787-826.

6. Bokenkamp D, Desai A, Yang X, Tai YC, Marzluff EM, et al. (1998) Microfabricated silicon mixers for submillisecond quench-flow analysis. Analytical Chemistry 70: 232-236.

7. Ehrfeld W, Golbig K, Hessel V, Löwe H, Richter T (1999) Characterisation of mixing in micromixers by a test reaction: Single mixing units and mixer arrays. Industrial \& Engineering Chemistry Research 38: 1075-1082.

8. Peel J, Howarth CR, Ramshaw C (1998) Process intensification: HIGEE seawater deaeration. Chemical Engineering Research \& Design 76: 585-593.

9. Ramshaw C (1981) HIGEE distillation - An example of process intensification. Chemical Engineering Journal, pp: 13-14.

10. Tuckerman DB, Pease RFW (1981) High-performance heat sinking for VLSL. IEEE Electron Device Letters, EDL 2: 126-129.

11. Mundinger D, Beach R, Benett W, Solarz R, Krupke W, et al. (1988) Demonstration of high- performance silicon microchannel heat-exchanger for laser diode-array cooling. Applied Physics Letters 53: 1030-1032.

12. Fan XL, Chen H, Ding Y, Plucinski PK, Lapkin AA (2008) Potential of nanofluids to further intensify microreactors. Green Chemistry 10: 570-677.

13. Hamsen GJ (2007) Reactive distillation: The front-runner of industrial process intensification. A full review of commercial applications, research, scale-up, design and operation. Chemical Engineering and Processing 46: 774-780.

14. Adris AM, Elnashaie S, Hughes RA (1991) A fluidized-bed membrane reactor for the steam reforming of methane. Canadian Journal of Chemical Engineering 69: 1061-1070.

15. Tsotsis TT (1992) Packed-bed catalytic membraine reactors. Chemical Engineering Science 47: 2903-2908.

16. Bavykin DV, Lapkin AA, Kolaczkowski SP, Plucinski PK (2005) Selective oxidation of alcohols in a continuous multifunctional reactor: Ruthenium oxide catalysed oxidation of benzyl alcohol. Applied Catalysis A- General 288: 175-184.
17. Ehrfeld W, Hessel V, Löwe H (2000) Microreactors: New Technology for Modern Chemistry. Weinheim, WILEY-VCH

18. Phillips CH, Lauschke G, Peerhossaini H (1997) Intensification of batch chemical processes by using integrated chemical reactor-heat exchangers. Applied Thermal Engineering 17: 809-824.

19. Boodhoo KVK, Jachuck RJ (2000) Process intensification: Spinning disk reactor for styrene polymerisation. Applied Thermal Engineering 20: 1127-1146.

20. Mahajan AJ, Kirwan DJ (1996) Micromixing effects in a two-impinging-jets precipitator. AIChE Journal 42: 1801-1814.

21. De Wilde J, Froment GF (2012) Computational Fluid Dynamics in chemical reactor analysis and design: Application to the ZoneFlowTM reactor for methane steam reforming. Fuel 100: 48-56.

22. Ehrfeld W (2000) Microreaction Technology: Industrial Prospects. Springer Berlin Heidelberg.

23. Ge H, Chen G, Yuan Q, Li H (2007) Gas phase partial oxidation of toluene over modified $\mathrm{V}_{2} \mathrm{O}_{5} / \mathrm{TiO}_{2}$ catalysts in a microreactor. Chemical Engineering Journal 127: $39-46$.

24. Commenge JM, Falk L, Corriou JP, Matlosz M (2005) Analysis of microstructure reactor characteristics for process miniaturization and intensification. Chemical Engineering and Technology 28: 446-458

25. Commenge JM, Falk L, Corrio JP, Matlosz M (2002) Optimal Design for Flow Uniformity in Microchannel Reactors. AIChE Journal 48: 345-358.

26. Kumar V, Paraschivoiu M, Nigam KDP (2011) Single-phase fluid flow and mixing in microchannels. Chemical Engineering Science 66: 1329-1373.

27. Kadowaki M, Yamamoto A, Mori S, Suzuki M (2007) Modeling of plasma CVD on the inner surface of a microchannel. Thin Solid Films 515: 4197-4202.

28. Zanfir M, Gavriilidis A (2003) Catalytic combustion assisted methane steam reforming in a catalytic plate reactor. Chemical Engineering Science 58: 3947 3960.

29. Rouge A, Spoetzl B, Gebauer K, Schenk R, Renken A (2001) Microchanne reactors for fast periodic operation: the catalytic dehydration of isopropanol. Chemical Engineering Science 56: 1419-1427.

30. Hessel V, Renken A, Schouten JC, Yoshida J (2009) Micro Process Engineering: A Comprehensive Handbook. Weinheim: Wiley-VCH.

31. Irani M, Alizadehdakhel A, Pour AN, Hoseini N, Adinehnia M (2011) CFD modelling of hydrogen production using steam reforming of methane in monolith reactors: Surface or volume-base reaction model? International Journal of Hydrogen Energy 36: 15602-15610.

32. Lange T, Heinrich S, Liebner C, Hieronymus H, Klemm E (2012) Reaction engineering investigations of the heterogeneously catalyzed partial oxidation of o-xylene in the explosion regime using a microfixed bed reactor. Chemical Engineering Science 69: 440-448.

33. Pan M, Tang Y, Yu H, Chen $\mathrm{H}$ (2009) Modelling of velocity distribution among microchannels with triangle manifolds. AIChE Journal 55: 1969-1982.

34. Williams KA, Horn R, Schmidt LD (2007) Performance of mechanisms and reactor models for methane oxidation on Rh. AIChE Journal 53: 2097-2113.

35. Löwe H, Ehrfeld W, Hessel V (2000) Micromixing technology. AlChE Topical Conf. Proc., pp: 31-47.

36. Holladay JD, Wang Y, Jones E (2004) Review of developments in portable hydrogen production using microreactor technology. Chem Rev 104: 4767-4789.

37. Zhai $X$, Ding S, Cheng Y, Jin Y, Cheng Y (2010) CFD simulation with detailed chemistry of steam reforming of methane for hydrogen production in an integrated micro-reactor. International Journal of Hydrogen Energy 35: 5383-5392.

38. Kiwi-Minsker L, Renken A (2005) Microstructured reactors for catalytic reactions. Catalysis Today 110: 2-14.

39. Uriz I, Arzamendi G, Diéguez PM, Laguna OH, Centeno MA, et al. (2013) Preferential oxidation of $\mathrm{CO}$ over $\mathrm{Au} / \mathrm{CuOx}-\mathrm{CeO} 2$ catalyst in microstructured reactors studied through CFD simulations. Catalysis Today 216: 283-291.

40. Environmental Permitting Guidance (2010) The Solvent Emissions Directive: For the Environmental Permitting (England and Wales).

41. Lin JN, Wan BZ (2004) Reaction Kinetics of Propane Catalytic Combustion on $\mathrm{Cr} /$ ?- $\mathrm{Al}_{2} \mathrm{O}_{3}, \mathrm{Co} / \mathrm{Cr} /$ ?- $\mathrm{Al}_{2} \mathrm{O}_{3}$, and $\mathrm{Au} / \mathrm{Cr} /$ ? $-\mathrm{Al}_{2} \mathrm{O}_{3}$. Journal of the Chinese Institute of Chemical Engineers 35: 149-159. 
Citation: Odiba S, Olea M, Hodgson S, Adgar A, Russell PA (2016) Computational Fluid Dynamics in Microreactors Analysis and Design: Application to Catalytic Oxidation of Volatile Organic Compounds. J Chem Eng Process Technol 7: 297. doi:10.4172/2157-7048.1000297

42. White FM (1999) Fluid Mechanics. 4th edn. McGraw-Hill.

43. Hartnett JP, Kostic M (1989) Heat transfer to Newtonian and non-Newtonian fluids in rectangular ducts. Advances in Heat Transfer 19: 47-356.

44. Li H, Olsen MG (2006) Aspect Ratio Effects on Turbulent and Transitional Flow in Rectangular Microchannels as Measured with MicroPIV. Journal of Fluids Engineering 128: 305-315.

45. http://www.engineeringtoolbox.com/air-properties-d_156.html

46. Madhvanand K, Renken A, Kiwi-Minsker L (2014) Microstructured Devices for Chemical Processing. Wiley-VCH.

47. http://www.nist.gov/data/PDFfiles/jpcrd1.pdf
48. Debray F, Franc JP, Maître T, Reynaud S (2001) Measurement of forced convection heat transfer coefficiets in mini-channels. Mecanique \& Industries 2: 443-454.

49. Saber M, Commenge JM, Falk L (2009) Rapid design of channel multi-scale networks with minimum flow maldistribution. Chemical Engineering and Processing: Process Intensification 48: 723-733.

50. Tonomura O, Tanaka S, Noda M, Kano M, Hasebe S, et al. (2004) CFD-based optimal design of manifold in plate-fin microdevices. Chemical Engineering Journal 101: 397-402.

51. Anderson JD (1995) Computational fluid dynamics: The basics with applications McGraw-Hill, Inc., 1st edn. Hemisphere Publishing, New York, NY, USA.
Citation: Odiba S, Olea M, Hodgson S, Adgar A, Russell PA (2016) Computational Fluid Dynamics in Microreactors Analysis and Design: Application to Catalytic Oxidation of Volatile Organic Compounds. J Chem Eng Process Technol 7: 297. doi:10.4172/2157-7048.1000297
OMICS International: Publication Benefits \& Features

\section{Unique features:}

- Increased global visibility of articles through worldwide distribution and indexing

- Showcasing recent research output in a timely and updated manner

Special issues on the current trends of scientific research

Special features:

- $700+$ Open Access Journals

$50,000+$ editorial tean

Rapid review process

Quality and quick editorial, review and publication processing

Indexing at major indexing services

Sharing Option: Social Networking Enabled

Authors, Reviewers and Editors rewarded with online Scientific Credits

- Befter discount for your subsequent articles

Submit your manuscript at: http://www.omicsonline.org/submission 